O educador contribui para a formação do senso moral do aluno não tanto pelo que transmite oralmente, mas por meio de sua prálica cotidiana e de seu estilo. Nesta pesquisa, analisamos as repercussòes que certas práticas escolares têm sobre o desenvolvimen. to moral, focando uma modalidade especifica de indisciplina: os furtos. Depois, apresentamos um caso de compreensĩo e enfrentamento de furtos, que favorece o descnvolvi: mento moral e a inclusão escolar dos alunos envolvidos, bem como propicia o amadurecimento do resto da turma. Partimos da psicanálise de Winnicott, que estuda o homem inserido na cultura, propóe o espaço potencial, entre o mun. do externo e o interno, como campo de pesquisa e intervenção.

Psicanálise; ética; educação

MORALITY, ETHICS AND SCHOOL INCLUSION

The educator contributes to form the student's moral sense, not only for what he/she transmits orally, but mainly through his/her daily practice and his/her behaviour. In this rescarch, we analyze the eflects that some school practices have on the moral devclopment, focusing on a specific modality of indiscipline: thefis. Then, we present a case of understanding and dealing with thefts that helps the moral

development and school inclusion of the students involved, as well as maturing the rest of the group. We start from the psychoanalysis of Winnicott, which studies the man inserted in the culture and proposes the potential space, between the external and the internal world, as research field and intervention.

Psychoanalysis; ethics; cducation

\section{MORALIDADE, ÉTICA E INCLUSÃO \\ ESCOLAR: FURTOS NA ESCOLA}

\author{
Cintia Copit Freller
}

"A

temática da moralidade, e de uma construção de valores pessoais socialmente justificados, não tem sido muito valorizada em nossa sociedade e até mesmo na estrutura de nossas escolas", constata Araújo (1996). Desde a extinção das disciplinas de Educação Moral e Cívica e Estudos de Problemas Brasileiros, as escolas vêm trabalhando ética com seus alunos de forma indireta e pouco sistemática. Estas matérias eram estruturadas de forma que se inculcassem nos alunos valores e ideais políticos da classe dominante, por transmissão oral, produzindo submissão e aquiescência.

Os Parâmetros Curriculares Nacionais (Brasil, 1997) e as novas Diretrizes Curriculares para o Ensino Fundamental aprovadas pelo Conselho $\mathrm{Na}$ cional de Educação em 1998 propõem a inserção transversal de conteúdos relacionados à ética aos conteúdos tradicionais do currículo escolar. Reco-

Psicanalista, mestre e doutora em Psicologia Escolar pelo Instituto de Psicologia da Universidade de São Paulo; psicóloga do Instituto de Psicologia da Universidade de São Paulo e orientadora educacional do Colégio Santa Cruz. 
nhece-se, desta maneira, que as escolas brasileiras devem preocuparse em formar jovens por meio de uma educação moral calcada em valores de justiça, igualdade de direitos e cidadania.

O grande desafio dos educadores brasileiros, continua Araújo, é realizar essa tarefa respeitando a autonomia dos sujeitos, considerando os interesses pessoais e coletivos, os valores de cada cultura, bem como aqueles universalmente desejáveis, sem basear-se na mera transmissão da cultura da classe dominante.

Com maior ou menor consciência, o educador contribui para a formação do senso moral do seu aluno, não tanto pelo que transmite oralmente, mas por sua prática cotidiana, pelos conteúdos que elege para socializar, pela forma com que conduz o processo ensino-aprendizagem, por seu modo de ser, pelo tipo de contrato que estabelece com as crianças, pela maneira de transmitir e negociar regras, pelo modo com que reage às transgressões de regras etc.

É urgente analisar as repercussões que as práticas escolares têm sobre o desenvolvimento moral, para que o educador possa se apropriar de forma consciente, intencional e crítica deste importante papel social que the pertence.

Já existem trabalhos que refletem sobre alternativas de articular ética e valores ao currículo regular, como conteúdos transversais, pois, como afirmam os construtivistas, não é eficaz transmitir valores oralmente, em uma disciplina à parte.

Neste artigo, abordaremos a possibilidade de trabalhar valores morais por meio de práticas escolares cotidianas, bem como no enfrentamento de situações de indisciplina ou de conflitos.

Discutiremos a finalidade da educação moral, ou seja, o tipo de moral cuja busca consideramos desejável, bem como alternativas para o educador ajudar a formá-la, por meio de um trabalho realizado em uma escola. Refletiremos também sobre possíveis articulações entre inclusão escolar e desenvolvimento moral, a partir dos resultados deste trabalho.

\section{FURTOS NA ESCOLA}

Partiremos da reflexão sobre uma das modalidades mais delicadas de indisciplina escolar: os furtos. Furtos são ocorrências comuns em escolas, sejam particulares ou públicas. Furta-se tudo: dinheiro, objetos, pastas, cadernos, roupas etc. Também são ocorrências comuns em nossa sociedade, em que se furtam, além de bens materiais, informações, direitos, tempo, espaço etc. 


\section{Dossiê}

Há quem defenda que os furtos fazem parte da história do nosso país, que começou com portugueses roubando os índios e continua com políticos apropriando-se de bens públicos indevidamente. Não podemos, no entanto, naturalizar tais acontecimentos, especialmente quando ocorrem nas escolas.

Furtos em escolas, como outros atos de indisciplina, sempre comunicam algo que merece ser compreendido para ser enfrentado eficazmente. Os furtos são uma categoria especial de indisciplina, pois sempre resultam em constrangimento moral. Podem ser enquadrados na definição de violência, de acordo com o Dicionário Aurélio: "Manifestação que causa constrangimento físico ou moral; uso da força, coação"...

Um aluno que corre pela classe, que grita na aula, que picha uma porta, ou que não obedece não está, necessariamente, constrangendo física ou moralmente alguém. Pode estar apenas agindo diferente do que espera dele seu professor. Já o aluno que furta está tirando algo de alguém e, portanto, causando-lhe um prejuízo. É sempre um ato anti-social, no sentido winnicottiano do termo, pois produz certo incômodo. Para Winnicott, uma das características dos atos anti-sociais, como veremos adiante, é incomodar.

Um colega indisciplinado, muitas vezes, é admirado pelo grupo e considerado um herói. Serve como porta-voz das insatisfações dos demais. Recebe, portanto, reclamaçōes e castigos dos adultos, porém, é bem visto pelo grupo e dele continua fazendo parte. Um colega que furta, 
além de ser reprovado pelos adultos, também é rejeitado pelo grupo, que o exclui. Muitos dos atos de indisciplina são interpretados pelos alunos como comportamentos de oposição e desafio ao mundo adulto e institucional. Já os furtos são compreendidos pelos jovens como ataque ao grupo, como atitudes prejudiciais aos pares, que geralmente isolam e excluem aquele que comete tais atos.

Portanto, no caso de furto, como de outros atos de indisciplina, precisamos conhecer o contexto em que ocorre, desvelar o que comunica, identificar seus determinantes, discriminar as pessoas envolvidas e pensar em como reparar os seus efeitos. No caso dos furtos, no entanto, além de problematizar tais acontecimentos e abrir outros canais de expressão, precisamos também nos preocupar em garantir a inclusão dos jovens que furtam ao grupo.

Dependendo de como realizamos o trabalho com os furtos na escola, contribuímos para o desenvolvimento moral dos jovens, bem como para a inclusão escolar de alguns deles. O educador, mais do que preocupar-se em encontrar os objetos furtados, devolvê-los aos seus antigos donos e punir os culpados, deve aproveitar essa bem como outras situações de indisciplina ou de conflito, e propiciar a formação ética dos alunos.

\section{BASES DO TRABALHO}

Queremos formar jovens éticos, preocupados com o bem comum, solidários, que possam criar e refletir criticamente sobre regras e, portanto, possam incorporá-las e interiorizá-las quando forem úteis para a sociedade. Não queremos produzir jovens submissos, adaptados, adequados socialmente, conformados, que cumpram regras pelo medo da punição ou pelo interesse em vantagens pessoais.

Sabemos que a escola desempenha um importante papel na estruturação e na evolução da moralidade.

Piaget pressupõe a existência de duas tendências morais: heterônoma e autônoma. A criança nasce sem noção de regras e sua utilidade. Posteriormente, pratica as regras de forma imitativa e egocêntrica, percebendo-as como sagradas e imutáveis. Esta é a moral da heteronomia que pode evoluir para uma moral mais autônoma, dependendo da qualidade da interação do indivíduo com o meio. Uma criança mais autônoma tem consciência das regras como um produto social e entende que cabe aos indivíduos elaborá-las, negociá-las e cumpri-las em função das necessidades do grupo. 
Para o autor, as virtudes morais, como a veracidade, a solidariedade, a responsabilidade etc., não são ensinadas por transmissão verbal, mas formadas no decorrer do desenvolvimento do individuo por um meio ambiente facilitador. Ele afirma que relações de cooperação com predomínio do respeito mútuo possibilitam a descoberta das regras como produto do homem para facilitar o convívio social. Ou seja, homens autônomos criam, entendem as leis e a elas obedecem por considerá-las necessárias para si e para os outros.

Para ele, uma escola que se preocupa em propiciar a formação moral autônoma privilegia o trabalho conjunto entre as crianças, já que este supõe cooperação e relações de reciprocidade. No decorrer do trabalho escolar feito em grupo, ocorrem a ajuda recíproca, o respeito na discussão, a conciliação bem como as dificuldades. As crianças precisam criar regras ou recorrer às existentes para regular suas ações e desenvolver a atividade proposta. Assim, grande parte das regras é recriada, elaborada e negociada a partir das necessidades naturais de convivência entre os alunos. Outras regras podem ser apresentadas pelo adulto, pode-se refletir sobre elas e negociá-las.

Winnicott, partindo de paradigma diferente, complementa a discussão proposta por Piaget, sem focar os aspectos cognitivos da moralidade. Ambos compartilham de visões semelhantes sobre o tipo de moralidade desejável, sobre a maneira de formá-la na nossa sociedade e sobre o papel da escola, lugar privilegiado para propiciar o desenvolvimento ético nos jovens - o discernimento do que é moral.

Winnicott entende como saudável o indivíduo que se preocupa e se importa com o outro, aceita responsabilidades, pode realizar uma atividade construtiva no mundo, e dele participar de forma pessoal e criativa.

Para ele, o fundamento da moralidade pessoal não pode ser ensinado, mas emerge da experiência de uma relação agressiva com o mundo, que pode ser reparada e transformada em uma relação positiva com o meio e com as pessoas.

A agressão, para o autor, é um componente originário da relação de objetos, pois a sua raiz faz parte do instinto que busca relacionamento. É, portanto, uma das fontes da energia de vida e está intimamente relacionada ao processo criativo, à espontaneidade e à motilidade. Sendo parte essencial do impulso amoroso primitivo que busca relacionamento, é evidência de vida, e não de morte. O amor é agressivo por acaso, já que não há intenção de machucar.

Em Winnicott, a agressão não emerge da frustração que o encontro com a realidade produz; ao contrário, a destrutividade é responsável por criar a qualidade de externalidade, necessitada pelo indivíduo. Também não se trata de pulsão de morte, ao contrário, trata-se de uma agressividade que busca relacionamento, busca vida. Nas fases iniciais do processo maturacional, o bebê não tem intenção de destruir. Ele espera encontrar algo em algum lugar e experimenta uma tensão instintual, que 
facilita e permite que a busca de relacionamento se efetive.

Em sua teoria do amadurecimento o bebê nasce em um estado de não-integração, em que não percebe a realidade como externa e também não se dá conta da sua agressividade; parte do processo de amadurecimento e da criação da realidade. Quando alcança uma relativa integração e pode reconhecer o mundo como externo, o bebê começa a perceber que está agredindo e machucando a mesma pessoa a quem ama e de quem depende. Passa então a se preocupar com a pessoa amada, e procura ser construtivo. Se a mãe-ambiente puder sustentar a situação e receber a reparação imaginativa desenvolvida pela criança, estabelece-se um círculo benigno em que a culpa pode ser suportada e a crença no esforço construtivo, resgatada. Ao perceber que a mãeambiente tolerou o ataque, os impulsos destrutivos ficam toleráveis e a criança preocupa-se em reparar e contribuir.

A criança precisa experimentar o círculo benigno em que pode machucar, depois reparar, mesmo que imaginativamente, elaborar a experiência e retomar o contato com o objeto atacado. Desta forma adquire confiança em sua capacidade para construir, sua vida instintiva adquire liberdade de expressão e não precisa inibir seus impulsos, ficando incapaz de brincar e de trabalhar. Este círculo benigno precisa ser experimentado em diversas etapas de seu processo de amadurecimento, e a escola tem um importante papel no sentido de propiciar constantemente esta vivência positiva.

$\mathrm{O}$ indivíduo agride ao mesmo tempo em que protege o objeto. A proteção ao outro se contrapõe à agressão e a restringe; é um movimento pessoal, e não imposto de fora para dentro, como um controle moral. O autocontrole e a moral significativa, nesta perspectiva, não são produzidos pelo limite que vem de fora.

Loparic mostra que Winnicott concebe uma moral que não vem da lei nem da proibição. Em Freud, o imperativo básico moral surge da proibição do incesto. Para Winnicott, a moral não surge da proibição de nada; a mãe que proíbe é intrusiva, está moralizando e submetendo. Para restringir o seu bebê, ela sobrevive e, ao sobreviver, adquire alteridade em relação a ele. Ao ser outra, externa, o bebê sente que precisa pagar por sua satisfação instintual. Ele percebe a existência de algo que não é ele. Logo, a restrição é criada pelo próprio movimento do bebê para modificar o objeto mãe em dois estados de relação com ela (excitada e tranqüila). $O$ mesmo ocorre em relação à sociedade. $\mathrm{O}$ indivíduo vai em direção à sociedade porque precisa do outro, procura o outro. $O$ mundo não oferece tudo o que o indivíduo necessita, e ele, então, constata que existem limites. O código moral é uma estilização desse mesmo fenômeno.

Assim, o cuidado dedicado à criança no sentido de favorecer o processo maturativo é mais útil e eficiente do que a educação, quanto à implantação de valores sociais e sanções. "A educação moral segue-se naturalmente à chegada da moralidade na criança, pelos 
processos de desenvolvimento natural que é favorecido pelo cuidado adequado" (Winnicott, 1990, p. 94).

Costa também defende a idéia de que os indivíduos necessitam conviver com outros e participar da cultura, por isso aceitam e criam limites. Não é a cultura, essencialmente violenta, que deve impor ao indivíduo limites contra as suas necessidades. Ele mostra que "na leitura de origem freudiana, a função do poder é a repressão dos excessos pulsionais, donde a importância da interdição; na de origem winnicottiana, o poder se revela na capacidade do ambiente de tolerar, sem revide, o ímpeto das pulsões, dirigindo-o para a expansão da criatividade. A cada um, diríamos, sua Holanda. A metáfora preferida de Freud é o dique holandês edificado para conter o avanço do mar e a inundação iminente; a de Winnicott é o moinho de água ou vento, que aproveita a força da natureza para a realização de trabalhos úteis" (Costa, 2000, p. 10).

Ele afirma que a força agressiva é motor da integração do ego e propulsora da criatividade; portanto, jamais pode ser inibida ou paralisada, para não comprometer o desenvolvimento saudável do indivíduo. Em Winnicott, continua Costa, "o interdito não domestica a violência das pulsões, representando a ordem simbólica coercitiva. O interdito é requerido pela pulsão para nutrir seu ímpeto e superar, de forma criativa, a agressividade do outro" (p. 21).

Para Safra, existe um desenvolvimento ético próprio ao individuo que, no decorrer do seu processo de amadurecimento, vai descobrindo o 
que rege a sua vida, a vida do outro, as relações e, então, desenvolve uma ética pessoal. O limite que a criança encontra é o limite criado. Ao encontrar no mundo leis que não preservam a ética do ser e são anti-humanas, o indivíduo transgride, pois encontra uma lei externa a si próprio, que não foi criada por ele. A transgressão é a forma que encontra para afirmar uma dignidade diante de uma situação que esgarça a sua humanidade. Winnicott mostrou que, em alguns casos, a única possibilidade de o indivíduo tentar estabelecer uma identidade, geralmente sem conseguir, é por meio da violência.

\section{O TRABALHO NA ESCOLA}

Partindo desses estudos, refletiremos sobre práticas escolares que nós, educadores, podemos desenvolver nas escolas, no dia-a-dia e em situações de conflito.

A longo prazo, contribuímos para o desenvolvimento moral dos alunos, ao desenvolver práticas escolares respeitosas, que cumprem seu papel educativo e propiciam aos jovens relações pessoais, críticas e criativas, com a cultura herdada e com os colegas.

Também procuramos estabelecer um ambiente justo, coerente e fidedigno, em que as regras são elaboradas em conjunto ou expostas, esclarecidas e negociadas com o grupo.

Propiciamos um espaço favorável em que o indivíduo possa desenvolver sua capacidade moral própria, assim como seu próprio modo de utilizar a cultura escolar. Isso inclui apresentar-lhe valores e normas da cultura em que vive, assim com de culturas passadas. Apresentar não significa impor ou implantar por meio da exigência de obediência e adaptação a esses códigos.

Preocupamo-nos em oferecer aos alunos oportunidades de participar da escola, contribuindo com o que podem para o seu bom funcionamento, pois, segundo Winnicott, eles lucram mais ao contribuir com a comunidade do que recebendo educação moral oral.

Nesse ambiente, atos de indisciplina são menos freqüentes. pois mais canais de comunicação estão abertos. Ainda nesses ca' is, furtos e outras manifestações de indisciplina ocorrem. Como enfrentá-las?

Uma intervenção adequada, feita sob medida, deve ser planejada de acordo com a mensagem que o furto comunica, dependendo do contexto em que ocorre, da sua freqüência, enfim, da especificidade de cada caso. Se é um pedido de ajuda, devemos aju- 
dar; se é um pedido de limite, devemos limitar; se é sintoma de uma tendência moral menos desenvolvida, precisamos propiciar condições de desenvolvimento moral etc.

A criança que furta pode ter um senso moral menos desenvolvido, heterônomo. Em outros casos, pode ser uma ação consciente no sentido de reduzir desigualdades, como roubar para dar aos mais necessitados, no estilo "Robin Hood", por exemplo. Pode ser apenas transgressão de uma regra. Pode ser um desafio, ou até mesmo uma forma de chamar atenção. Pode ser uma "doença", como a tendência anti-social, postulada por Winnicott. Há quem afirme ser manifestação de "má índole".

Não há uma única maneira de agir. Cada caso é um caso, e devemos tentar entender as especificidades de cada situação para propor uma intervenção adequada. Desta forma, o exemplo que segue não deverá servir como modelo, mas como disparador de reflexão.

\section{ESTUDO DE CASO: ENFRENTANDO OS FURTOS}

Quase diariamente éramos procurados por alunos reclamando de que objetos, dinheiro e até material escolar tinham sumido. Acusavam colegas, reclamavam, choravam. Conversávamos particularmente com eles, no intuito de entender melhor a situação, acolher suas queixas, acalmá-los.

Como o problema piorava, decidimos conversar abertamente com a turma sobre o que estava acontecendo. Fomos de classe em classe escutar a versão dos alunos, pensar com eles sobre o que poderia estar produzindo tais situações e obter sugestões para enfrentá-las.

A possibilidade de uma interlocução verdadeira com um grupo de alunos parece fácil, mas não é. Corremos pelo menos dois riscos quando conversamos com os alunos: o primeiro é chamar de conversa um discurso de outra ordem. Conselho, ordem, bronca, recriminação não podem ser chamados de conversa. Fingir que escutamos os alunos quando não estamos abertos para entendê-los, para acolher suas queixas e para acatar ou negociar algumas de suas sugestões, é um faz-de-conta, e não uma conversa. O outro risco é virar a vara para o outro lado e agir como alguns críticos de Piaget entendem ser sua proposta para a educação, ou seja, o educador conversar com os alunos como se fossem amigos. 
O educador ocupa um lugar diferente dos alunos e só exerce sua autoridade democraticamente quando consegue liderar uma discussão, escutar de fato a classe, sem esquecer que representa uma cultura, uma instituição, tem um saber e um objetivo com aquela conversa. O educador não é um igual, mas um mediador entre o passado e o presente, entre os interesses da instituição e do grupo de alunos, possibilitando a solução dos conflitos e o desenvolvimento das tarefas e das relações inerentes ao processo educativo. Ele pode considerar ser eficaz pedagogicamente, para alcançar seus objetivos, propiciar muitos momentos de relações de cooperação entre os alunos, sem demasiada interferência do adulto. Porém, ele favorece esse tipo de interação de forma responsável e intencional, ao entender que os alunos se beneficiam desse tipo de vivência. O mesmo ocorre em relação ao limite entre o adulto e o jovem. Para ser eficiente, o adulto deve impor ao jovem o limite que ele necessita e pede. Nada impede, e é até salutar, que o adulto sinta raiva e mostre ao jovem que sua atitude o machuca, demonstrando sua irritação e impedindo o ataque concreto. Porém, a verdadeira moral é construída pelo adolescente, a partir da percepção de que está machucando aquele que respeita. Assim ele próprio se limita, ou pede ao adulto que o ajude a se limitar.

Além da conversa sobre os furtos que estavam acontecendo com aquela turma, naquele ano, ampliamos e aprofundamos a discussão sobre o assunto, aproveitando para contar histórias de furtos em nosso país e no mundo. Pensávamos com eles, no decorrer das histórias que contávamos e que eles também contavam, em como era variável a maneira de interpretar e de enfrentar furtos em função do contexto, do momento histórico etc.

Era mais uma oportunidade para os jovens conhecerem fatos passados, pensarem criticamente sobre eles e aproveitarem para tentar dar um rumo distinto ao seu presente. É papel do educador, como afirma Guimarães (1999, p. 173), penetrar no passado e retomar o fio de uma história que não foi contada. Assim, contamos não só os eventos realizados, mas também o que não pôde acontecer e os porquês de a história ser contada desta maneira. "Uma alternativa para a educação talvez esteja na possibilidade de nos determos na história deste país como ele é, de modo que as coisas invisíveis, ou que ficaram ocultas, reprimidas, possam se dar a ver, lentamente, e não se percam na indiferença do nosso olhar. Ao invés de continuarmos repetindo o que fomos no passado, podemos recuperar o sentido inédito, rompendo a continuidade linear da história” (p. 174).

Nosso esforço é trazer à memória o que foi esquecido, a história do mundo, a história do grupo, da classe e a história pessoal de cada um.

Com essas conversas, lidamos com alguns aspectos do problema e estudamos algumas medidas práticas para evitar sumiços e pensamos em como cada um cuidar melhor de suas coisas. Combinamos, também, que ninguém acusaria um outro sem ter certeza, além de outras medidas 
práticas como fechar a sala, entregar para a vigilante os objetos encontrados etc.

Mesmo com essa troca de idéias, porém, não conseguimos atingir concepções mais profundas e subjetivas, tais como crenças, preconceitos, medos, ansiedades, vergonha etc.

Decidimos então discutir com a classe alguns dilemas morais sobre furto.

O trabalho com os dilemas morais, proposto por Kohlberg, é permitir que um grupo seja exposto a raciocínios morais levemente superiores aos próprios, o que leva a um desequilíbrio seu modo de pensar habitual, promovendo mudanças na direção do desenvolvimento do raciocínio moral. O autor entende que pôr jovens para debater questões controversas com outras pessoas que estejam em estágios morais mais elevados que os deles propicia o avanço moral. Menin (1996) expõe detalhadamente as idéias de Kohlberg, bem como fornece exemplos, que usamos em nosso trabalho, de histórias com dilemas morais envolvendo furtos.

Puig (1999) também propõe a discussão, com alunos, de dilemas morais, adaptados de Kohlberg e Blatt, para facilitar o desenvolvimento do juízo moral. Ele apresenta os dilemas como breves narrações que apresentam conflitos de valores ou fatos problemáticos, obrigando os jovens a refletir, argumentar e justificar a alternativa que thes parece mais justa.

Os dilemas morais podem ser considerados situações-problema, pois colocam o aluno "em situações que o obrigam a alcançar uma meta, a resolver um conflito, a tomar decisões" (Perrenoud, 2001, p. 60). O estudante será levado a construir competências confrontando-se com conflitos, problemas, complexos e realistas, que mobilizem recursos cognitivos, morais e afetivos. Os dilemas morais são desafios em que os alunos se envolvem para solucioná-los, pois estão pessoalmente implicados neles. São problemas incluídos em uma situação que faça sentido para eles, desequilibram o estágio moral em que se encontram, obrigando-os a buscar novas razões e novos parâmetros para resolvê-los. "A discussão em grupo favorece o reconhecimento de pontos de vista, interesses e opiniões distintos. A heterogeneidade de perspectivas assim como as diversas contribuições dos participantes constituem uma condição inestimável para o desenvolvimento do juizo moral” (Puig, 1988, p. 67). Restabelece-se, então, o equilíbrio em um nível moral mais autônomo.

Essa estratégia mostrou ser uma alternativa interessante por, pelo menos, dois motivos: por um lado, possibilitou aos alunos com uma tendência moral mais heterônoma poderem expor sua opinião, sem que fossem recriminados pelos colegas. Os demais, que apresentavam uma moralidade mais autônoma, puderam também expor sua forma de pensar, justificá-la, argumentar e, muitas vezes, convencer os colegas. Esta troca de opiniões e argumentações entre alunos com estágios de moralidade diferentes foi rica para todos, desenvolvendo competências e propiciando o amadurecimento da turma. 
Dirigíamos a discussão e formulávamos perguntas que estimulavam os alunos a questionar os valores morais de forma mais livre, percebendo a multiplicidade de soluções em função da variedade de interpretações, facilitando a ampliação de suas perspectivas e a inclusão dos argumentos apresentados pelos colegas. Respeitávamos o pluralismo e a diversidade de opiniões, garantíamos o sigilo sobre os temas discutidos, problematizávamos os argumentos apresentados e dávamos oportunidade aos processos de diálogo e reflexão.

Além de favorecer o desenvolvimento moral, essa estratégia possibilitou outro efeito inesperado. Alguns alunos puderam, com o auxílio dos personagens das histórias, apresentar seus dramas pessoais, expor conflitos e ansiedades mais profundas, por meio dos mecanismos de projeção e identificação. Dentro dos limites de uma situação coletiva, esses conflitos puderam emergir, ser verbalizados e encaminhados para uma elaboração.

Contamos à classe, por exemplo, histórias como a de um menino pobre que roubava para alimentar um amigo, ou de um homem que roubava um remédio para salvar sua esposa ou ainda de uma menina que roubava uma fita apenas por vaidade. Refletimos com eles sobre as noções do certo e do errado, justo e injusto, se era possível considerar um roubo mais válido que outro e qual a pena que poderia ser indicada para cada situação.

Eles envolveram-se com as estórias e com a discussão. Uma turma até propôs que fizéssemos um julgamento com tribunal, juiz, testemunhas etc.
Essas reflexões incentivaram as crianças a pensar sobre as razões que impelem alguém a roubar, sobre as intenções, sobre os afetos e sobre os efeitos que produzem determinadas atitudes. Elas puderam ponderar que, algumas vezes, uma atitude pode ser ilegal, como um roubo, porém, pode ser motivada por intenções justas. Também se questionaram algumas penas injustas, aplicadas por práticas autoritárias, e não por autoridade legítima. Além disso, discutiram sobre a estrutura da nossa sociedade, "que algumas vezes é injusta, produzindo leis injustas", e sugeriram alternativas para lidarmos com tais situações. Elas concluíram que devemos tentar melhorar a sociedade e buscar atualizar algumas leis, e não simplesmente as transgredir por não concordarmos com elas.

De modo geral, as discussões propiciaram reflexão e possibilitaram avanços na maneira de entender $e$ enfrentar regularmente regras. As crianças iam falando, pensando, ouvindo a opinião do colega, e, às vezes, até mudando a sua em função dos argumentos dos outros. Algumas crianças puderam despertar para as forças reprimidas que as levaram a se conduzir desta forma, sem procurar ocultá-las mais ainda a ponto de se culpabilizarem e se censurarem até ficarem paralisadas.

Potencialmente, as discussões favorecem a abertura para um relacionamento que leve as crianças a despertarem em relação a anseios e necessidades, cobertos ou encobertos, que dirigem suas ações. Os colegas ficam mais abertos para com o tema, podendo entender melhor as inten- 
ções daquele que furta, sem julgá-lo previamente de modo maniqueísta como ladrão e merecedor de punições exemplares. Alguns perceberam que os furtos poderiam não ser atitudes que revelavam má índole, mas uma doença, uma necessidade, ou um pedido de atenção. Estavam mais dispostos a ajudar, e não só acusar.

Algumas vezes, após essas dinâmicas com a classe, o aluno que havia furtado algo pôde procurar o educador e devolver o objeto furtado.

Em outros casos, complementou-se o trabalho conversando com a criança que furtou e com seus pais. Eram casos em que havia uma dinâmica familiar mais comprometida, que merecia um trabalho mais profundo. Um dos casos expressava um pedido desesperado por limite e rigor do meio, até mesmo familiar, que era frágil e pouco confiável. Exercemos, escola e família, atuações firmes e coerentes, para possibilitar à criança reaver a capacidade perdida de encontrar objetos simbólicos, e não concretos, e retomar uma relação criativa com a realidade externa.

$\mathrm{O}$ trabalho em relação aos furtos não terminou por aí. Por mais bem conduzido que fosse, deixou nas crianças mais diretamente envolvidas certo mal-estar, embora nenhuma outra criança ou professor viesse a saber o nome delas. Estavam sem jeito, pouco à vontade. Sentiam-se excluídas, diferentes. Coube a nós, reintegrá-las de forma positiva no grupo, a fim de restabelecer o círculo benigno e a sensação de confiança e auto-estima. Furtaram, aproximaram-se das necessidades que as impeliram a furtar e refletiram sobre o papel que desempenham no grupo e, até agora (alguns meses já se passaram), não voltaram a furtar. Mas que mais poderíamos fazer a fim de despertar sua capacidade construtiva, se não abrir a possibilidade para eles contribuírem, sendo valorizados seus pontos positivos e seus êxitos?

Esses alunos, entre outros, foram escolhidos como líderes da organização de uma festa junina, papel que requeria muita responsabilidade e honestidade. Eles trabalharam duro, de forma competente e honesta, cuidando do dinheiro, que foi doado a uma instituição de caridade. Também foram escolhidos para guardar as apostilas dos alunos que estavam faltando, com o objetivo de entregá-las depois, explicando-lhes a matéria.

Todo esse esforço foi devidamente valorizado, e estamos confiantes de que iniciamos um trabalho no sentido de ajudá-los a procurar o que precisam no lugar certo e a expressar seus conflitos simbolicamente.

O coletivo saiu, moral e eticamente, mais desenvolvido, mais seguro de que furtos e outros conflitos voltarão a emergir, mas poderão ser compreendidos e enfrentados. Poderão, puxando o fio do passado, desamarrando os nós do presente, tecer um novo futuro. 
REFERÊNCIAS BIBLIOGRÁFICAS

Araújo, U. F. (1996). O ambiente escolar e o desenvolvimento do juízo moral infantil. In Macedo, L. (org.). Cinco estudos de educação moral. Sāo Paulo, SP: Casa do Psicólogo.

Brasil, Secretaria de Educação Fundamental (1997). Parâmetros Curriculares Nacionais - Ensino Fundamental. Brasilia, DF: MEC/SEF.

Costa, J. F. (1984). Violência e psicanálise. Rio de Janeiro, RJ: Graal.

--_- (2000). Plaidoyer pelos irmãos. In Kehl, M. R. (org.). Função fraterna. Rio de Janeiro, RJ: Relume Dumará.

Freller, C. C. (1993). Crianças portadoras de queixa escolar: um enfoque "winnicottiano". Dissertação de Mestrado. Instituto de Psicologia da Universidade de São Paulo, São Paulo, SP.

--- (1999). Pensando com Winnicott sobre alguns aspectos relevantes ao processo de ensino e aprendizagem. Psicologia USP, Vol. 10., $\mathrm{n}^{\circ}$ 2, 189-205.

--_-(2001). Histórias de indisciplina escolar: o trabalho de um psicólogo numa perspectiva winnicottiana. São Paulo, SP: Casa do Psicólogo.

Guimarães, A. M. (1999). Autoridade e tradição: as imagens do velho e do novo nas relaçōes educativas. In Aquino, J. (org.). Autoridade e autonomia na escola. São Paulo, SP: Summus.

Loparic, Z. (1996a). Winnicott e o pensamento pós-metafísico. In Catafesta, I. F. M. (org.). D. W. Winnicott na Universidade de São Paulo. São Paulo, SP: Lemos.

-_- (1996b). Winnicott: uma psicanálise não-edipiana. Percurso, 17.

Menin, M. S. S. (1996). Desenvolvimento moral. In Macedo, L. (org.). Cinco estudos de educação moral. São Paulo, SP: Casa do Psicólogo.

Patto, M. H. S. (1987). A produção do fracasso escolar. Tese de Livre-Docência,
Instituto de Psicologia da Universidade de São Paulo, São Paulo, SP.

Piaget, J. (1996). Os procedimentos da educação moral. In Macedo, L. (org.). Cinco estudos de educação moral. São Paulo, SP: Casa do Psicólogo.

Perrenoud, P. (2000). Dez novas competências para ensinar. Porto Alegre, RS: Artes Médicas.

(2001). Ensinar: agir na urgência e decidir na incerteza. Porto Alegre, RS: Artes Médicas.

Puig, J. M. (1988). Etica e valores: métodos para um ensino transversal. São Paulo, SP: Casa do Psicólogo.

Safra, G. (1995). Momentos mutativos em psicanálise: uma visão winnicottiana. São Paulo, SP: Casa do Psicólogo.

-_- (1999). A face estética do self, teoria e clínica. São Paulo, SP: Unimarco.

Winnicott, D. W. (1975). O brincar e a realidade. Rio de Janeiro, RJ: Imago.

--- (1980). A família e o desenvolvimento do indivíduo. Belo Horizonte, MG: Interlivros.

---- (1982). A criança e o seu mundo. Rio de Janeiro, RJ: Zahar.

--_ (1983). O ambiente e os processos de maturação. Porto Alegre, RS: Artes Médicas.

- (1987). Privação e delinqüência. São Paulo, SP: Martins Fontes.

(1988). Textos selecionados: da pediatria à psicanálise. Sâo Paulo, SP: Martins Fontes.

- (1989). Tudo começa em casa. São Paulo, SP: Martins Fontes.

--_ (1990). O ambiente e os processos de maturação. Porto Alegre, RS: Artes Médicas.

---- (1997). Pensando sobre crianças. Porto Alegre, RS: Artes Médicas.

---- (s.d.). Explorações psicanalíticas. Porto Alegre, RS: Artes Médicas.

Recebido em novembro/2001. 